\title{
Three challenges for the social determinants of health pursuit
}

\section{David V. McQueen}

David McQueen is a senior biomedical research scientist and Associate Director for Global Health Promotion at the National Center for Chronic Disease Prevention and Health Promotion (NCCDPHP), at the Centers for Disease Control and Prevention (CDC) in Atlanta, Georgia, USA.

Prior to CDC he was Professor and Director of the Research Unit in Health and Behavioral Change at the University of Edinburgh (1982-92)

For those who have worked over the years within a population health perspective of public health the current enthusiasm for the so-called social determinants of health (SDOH) is a welcome departure from the efforts to address single diseases and single causes. However one finds this enthusiasm embedded in a global health community that remains engaged primarily in a more limited and simplified role for public health. One can certainly specify any number of challenges that arise from the social determinants perspective. In this brief editorial I want to simply stress three tough lessons faced by the SDOH perspective. These three are: 1) the knowledge base for the SDOH is ancient; 2) the measurement of what is social is problematic; and 3) the evidence for what works to change the social determinants is weak.

First, the knowledge that there is a consistent and powerful association between social factors and health outcomes is not only well established, but well known for centuries. This is not the place to review ancient texts of Babylonia and Greece, rather to consider that even within the sphere of public health this is an old story. ${ }^{1}$ The idea that the health of populations is affected by and is a product of the social determinants in the population is not only an old belief, even perhaps an accepted truth, dates certainly from the work of the haberdasher John Graunt who published his book Natural and Political Observations Made upon the Bills of Mortality (1662) in the $17^{\text {th }}$ Century. ${ }^{2}$ In the $19^{\text {th }}$ Century Friedrich Engels pursued The Condition of the Working Class in England in $1844^{3}$; and in the late $19^{\text {th }}$ Century the great French sociologist Emile Durkheim demonstrated the relationship between social integration and suicide. ${ }^{4}$ Throughout the $20^{\text {th }}$ Century thoughtful work in the area of sociocultural factors in health illness continued, particularly in the fields of medical sociology and social medicine; the bulk of this large literature simply reinforced the "accepted truth" that linked social context to health-related outcomes. ${ }^{5}$ More recently we have the extensive work of the WHO Commission on Social Determinants. ${ }^{6}$ The tough lesson in all this long historical journey to show the relationship between social context and health is not the sudden enthusiasm in some quarters to accept this knowledge base, but the fact that centuries of repeating the obvious has not been able to create any "sense of urgency" to address these societal inflicted causes. Whether the recent report will finally marshal the forces to address the social determinants and improve population health remains to be determined.

Second, measurement and assessment of the social determinants remains an enormous challenge. To begin with, the world of public health has not historically spent much effort in trying to assess or measure that which is "social." Even a well established "social" variable such as socioeconomic class presents serious conceptual, methodological and measurement challenges. The often very simplified versions of this concept applied in much health research are often merely outdated indices of social position based on income and education, thus simplifying an extremely complex variable into a more simply measured one. Furthermore, many of the subsequent analyses then use this variable ignoring the underlying statistical and theoretical assumptions which underlie it. But this is a trivial problem compared to the challenges faced to accurately assess and measure many of the social determinants of interest. For example, the social context of health undoubtedly relates to the many positive and negative aspects of modern day urbanization, for example sprawl. Yet, a satisfactory measurement of the concept of sprawl that can be used to assess its relationship to health outcomes remains a challenge. It would be pleasant if measurement were the only serious methodological problem faced by those in public health; however the real challenge is to integrate such measures into ongoing surveillance systems across the globe. 
Given that there is to date no global comprehensive behavioral risk factor surveillance, ${ }^{7}$ it would appear to be a great stretch of the imagination that we will have any comprehensive surveillance and assessment of social determinants and their role in health and illness.

Third, and probably most significant, is the challenge of evidence. There is little doubt, based on centuries of research, that the etiological case for the role of social determinants in health has been made. If no further research were conducted we would have enough knowledge to move forward. But "evidence" of etiology and causation is distinct from the knowledge and evidence related to understanding interventions that can alter and effectively change the causal pathways. ${ }^{8}$ There is much to be done in this area. To begin with most models that characterize the role of social determinants in health are etiological and merely describe the known or hypothesized linkages between social determinants and outcomes. It is much more difficult to find models of interven- tion on the social determinants, let alone actual studies that have studied the process whereby such variables have been successfully changed. If one looks at the intersection between evidence and effectiveness, where the strength of the knowledge base for what works meets the agreement about translating the knowledge base into application, one finds few areas of certainty or standards about what works and how to do it. Indeed, most social determinants lie in an area of complexity characterized by multiple determinants, multiple intervention settings, multiple outcomes, multiple paradigms, cultural diversity, political diversity, and multiple potential interactions. So the challenge for those concerned with a public health that addresses the social determinants of health is to move the applied research agenda to the assessment of interventions that will change the social determinants. Unless effective interventions change the social determinants, we will be looking at the same or a worsening "gradient" in a decade. And, the historical story will continue as usual.

\section{References}

1. Rosen G. A History of Public Health. MD Publications, New York, 1958.

2. Graunt, J. Natural and Political Observations Made upon the Bills of Mortality. London, 1662.

3. Engels, Friedrich The Condition of the Working Class in England in 1844, (originally Die Lage der arbeitenden Klasse in England, Leipzig 1845 in German, 1887 in English ) Re-Published Oxford: Oxford University Press, 1993.

4. Durkheim E. Suicide, a study in sociology (1897). New York: The Free Press, 1997.
5. McQueen DV, Siegrist J. Sociocultural Factors in the Etiology of Chronic Disease. Soc Sci Med 1982;16:353-67.

6. Commission on Social Determinants of health. Closing the gap in a generation. Final report, WHO: Geneva, 2008.

7. McQueen DV, Puska, P (Eds.). Global Behavioral Risk Factor Surveillance. New York: Kluwer Academic/Plenum Publishers, 2003.

8. McQueen DV, Jones CM (Eds.eds. Global Perspectives on Health Promotion Effectiveness. New York: Springer Science \& Business Media. 2007.
The opinions expressed in the editorial are those of the author and do not necessarily reflect the views of the CDC.

Address for correspondence
Prof. David V McQueen
CDC/NCCDPH
Office of the Director MS K40
4770 Buford Highway NE
Atlanta 30341
USA
Tel.: +1-770-488-5403
Fax: +1-770-488-5971
E-mail: dvmcqueen@cdc.gov

